

\section{Do Conto ao Seriado: duas histórias}

\author{
From Tale to Series: two stories
}

\section{Patricio Dugnani}

121 PORTO ALEGRE | v. 22 | n. 38 | 2017 | p. 121-129 DOl: http://dx.doi.org/ 10.15448/1980-3710.2017.2.28145 Sessões do Imaginário

\section{Resumo}

Pretende-se, nessa pesquisa, analisar a estrutura narrativa dos seriados contemporâneos, com a estrutura narrativa do conto, para verificar se essas duas formas de expressão apresentam características comuns, e se existe uma influência do formato narrativa do conto literário, nos seriados televisivos contemporâneos. Parte-se da hipótese de que o primeiro influencia o segundo. Para realizar essa comparação serão utilizadas, principalmente, as análises e conceitos das estruturas narrativas da TV e dos seriados de Arlindo Machado, e de Marshall Mcluhan, os estudos sobre o conto de Ricardo Píglia e Nádia Gotlib, o conceito de intertextualidade de Roland Barthes e Leda Tenório da Motta.

\section{Palavras-chave}

Comunicação; seriado; conto; literatura; televisão.

\section{Abstract}

In this research, we intend to analyze the narrative structure of contemporary serials, with the narrative structure of the story, to verify if these two forms of expression present common characteristics, and if there is an influence of the narrative format of the literary tale, in the contemporary television serials. It starts from the hypothesis that the former influences the latter. In order to carry out this comparison, the analyzes and concepts of the narrative structures of TV and the series by Arlindo Machado and Marshall Mcluhan, studies on the story by Ricardo Píglia and Nádia Gotlib, the concept of intertextuality by Roland Barthes and Leda Tenório da Motta.

\section{Keywords}

Communication; series; story; literature; television. 


\section{Introdução}

Percebe-se atualmente um crescente interesse pelos seriados, não que eles não fossem cultuados desde o início da TV, e até anteriormente, nos cinemas no entanto parece que uma nova maneira de assistir os seriados tem se destacado na contemporaneidade, juntamente com os novos modelos de distribuição de conteúdo on demand, como Netflix.

Essa nova maneira de assistir os seriados, que tem contaminado o espectador, provém do poder desse mesmo consumidor de conteúdo (e, hoje, graças aos novos meios de comunicação, também produtor ativo de conteúdos de informação) de escolher a hora, o local, e a quantidade de episódios que ele pretende assistir, pois com esses novos meios de distribuição de conteúdos on demand, fica à critério do espectador, quando, onde, e quanto tempo ele pretende assistir seu seriado favorito. Existem alguns relatos de pessoas que ficam, por exemplo, o final de semana inteiro, para ver toda uma temporada de sua série favorita, e isso se torna, muitas vezes, um acontecimento, um evento que reúne grupos de pessoas, familiares e amigos, em torno da TV, para ver o desenrolar das intrincadas histórias narradas pelos seriados.

Observando as estruturas narrativas dos seriados, percebe-se uma constante interessante, e crescente, em suas histórias, uma característica cada vez mais comum: Os episódios apresentam, tanto uma ação individual e independente, ou seja, uma história que começará e acabará naquele espaço do episódio do dia, quanto apresentam uma parte de uma segunda narrativa simultânea. Uma narrativa que apresenta uma ação contínua, que vai se desenrolando no decorrer de todos os episódios. Para Arlindo Machado (2000), esse tipo de narrativa pode ser classificada como sendo uma construção teleológica, e trata-se de um tipo de narrativa comum de serialização que ocorre na TV.

O que chama a atenção desse tipo de estrutura narrativa dos seriados, é que ele, na verdade, não conta apenas uma história, mas duas, que por vezes são independentes, e por outras estão relacionadas a uma narrativa maior, que percorre todos os episódios. Esse fator chama a atenção, não quando comparamos às estruturas narrativas da própria TV, ou dos seriados, mas, de uma maneira intertextual e interdisciplinar, quando comparamos essa estrutura narrativa a um formato literário, anterior mesmo à invenção da TV, de todos os meios elétricos, e dos meios de comunicação de massa: o conto.

Essa comparação se dá à partir da visão de Ricardo Píglia (2004) para quem a narrativa de um conto é dupla, pois esse tipo de texto literário acaba por abarcar sempre duas histórias, uma que fica na superfície, e uma que emerge durante a história.

Em virtude dessa semelhança, pretende-se analisar a estrutura narrativa dos seriados contemporâneos, principalmente de formato teleológico, com a estrutura narrativa do conto, para verificar se, realmente, essas duas formas de expressão apresentam estruturas comuns, e se existe uma influência da estrutura narrativa do conto literário, nos seriados televisivos contemporâneos. Parte-se da hipótese de que o primeiro, influência o segundo.

Para realizar essa comparação serão utilizadas, principalmente, as análises das estruturas narrativas da TV e dos seriados de Arlindo Machado (2000), e de Marshall McLuhan (1996), os estudos sobre o conto de Ricardo Píglia (2004) e Nádia Gotlib (2006), o conceito de intertextualidade de Roland Barthes (2004) e Leda
Tenório da Motta (2011). Além desses conceitos, pretende-se eleger alguns casos para serem analisados, entre eles destacam-se o seriado The Blacklist (2013), e dos contos do livro Ficções (1999), de Jorge Luis Borges.

\section{As duas histórias e o conto}

Uma primeira dificuldade em se desenvolver esse tema, esbarra, segundo Nádia Gotlib (2006), em como se definir o conto, pois trata-se de uma forma narrativa muito antiga, que vai desde sua forma mais literária pura da contemporaneidade, até se cruzar em um tempo místico com as narrativas fundadoras das sociedades humanas, um tempo que pertence ao estudo da antropologia. Por isso apresenta os formatos mais diversos em suas diferentes construções, conforme os autores, conforme a cronologia e a cultura da produção.

Vários atentam para a dificuldade também de se explicar o conto. Julio Cortázar, em "Alguns aspectos do conto", refere-se a "esse gênero de tão difícil definição, tão esquivo nos seus múltiplos e antagônicos aspectos". Porque se, de um lado, "é preciso chegarmos a ter uma idéia viva do que é o conto", isto torna-se difícil "na medida em que as idéias tendem para o abstracto, para a desvitalização do conteúdo" (Gotlib, 2006, p. 10).

Nesse embate, Gotlib (2006), se apoiando em Julio Casares e Julio Cortázar, nos apresenta o conto a partir de três possibilidades. Na primeira, o conto é apresentado como um "relato de um acontecimento" (Gotlib, 2006, p. 11), ou seja, o contar de um fato que aconteceu, à princípio, no campo mais próximo da realidade. Já, na segunda concepção, o conto é apresentado, não 
como um recorte da realidade, mas sim, um "acontecimento falso" (Gotlib, 2006, p. 11), uma ficção. Enquanto na terceira, apresenta o conto como se fosse apenas uma fábula. De qualquer forma, ela conclui que o conto tem em comum, o ato de contar, narrar. Dessa forma é que pretende-se entender o conceito de conto, para essa análise: um conto é uma narrativa.

Para Julio Casares há três acepções da palavra conto, que Julio Cortázar utiliza no seu estudo sobre Poe: 1. relato de um acontecimento; 2 . narração oral ou escrita de um acontecimento falso; 3 . fábu-

la que se conta às crianças para diverti-las. Todas apresentam um ponto comum: são modos de se Contar alguma coisa e, enquanto tal, são todas narrativas (Gotlib, 2006, p. 11, grifos no original).

Sendo uma narrativa, espera-se do conto, no mínimo, ainda com base em Gotlib (2006), três estruturas básicas: uma ação, que se desenrole durante um tempo como uma "sucessão de acontecimentos", que não necessariamente tenha que obedecer às leis da física em relação ao seu espaço e tempo.

De fato, toda narrativa apresenta: 1. uma sucessão de acontecimentos: há sempre algo a narrar; 2 . de interesse humano: pois é material de interesse humano, de nós, para nós, acerca de nós: "e é em relação com um projeto humano que os acontecimentos tomam significação e se organizam em uma série temporal estruturada"; 3. e tudo "na unidade de uma mesma ação" (Gotlib, 2006, p. 11).

Depois de conceituar o conto, dessa maneira ge- ral, pretende-se agora procurar as características dessa estrutura literária, que pode ter pontos de intersecção com a organização narrativa dos seriados de TV. Para essa análise será utilizada o conceito que Ricardo Píglia desenvolve em seu livro Formas Breves (2004). Píglia apresenta, no capítulo Teses sobre o Conto uma primeira tese, onde afirma que esse tipo de texto tem uma narrativa dupla, ou seja, "um conto sempre conta duas histórias" (Píglia, 2004, p. 89).

Uma estaria na superfície, à mostra, evidente, e se apresentaria facilmente, porém, a outra, estaria mais na profundidade do texto, surgindo devagar, no decorrer da narrativa, e muitas vezes nas entrelinhas. As histórias são apresentadas de maneira independente, mas apresentam pontos de intersecção.

Cada uma das duas histórias é contada de modo distinto. Trabalhar com duas histórias quer dizer trabalhar com dois sistemas diferentes de causalidade. Os mesmos acontecimentos entram simultaneamente em duas lógicas narrativas antagônicas. Os elementos essenciais de um conto têm duplafunção e são empregados de maneira diferente em cada uma das duas histórias. Os pontos de interseção são o fundamento da construção (Píglia, 2004, p. 90).

Esse é o ponto que interessa para essa análise, essa duplicidade do conto, pois nessa questão é que será feita a intersecção entre o texto literário e a produção de séries de TV. Assim como o conto, boa parte dos seriados de TV contemporâneos apresentam essa duplicidade narrativa, pois enquanto o episódio é exibido, uma história se apresenta na superfície: um crime, um mistério, um roubo. Fato que, muitas vezes, é aparentemente independente, mas que se revela no decorrer do mesmo episódio, ou, em outros episódios da temporada, uma parte maior de uma grande trama, que se desenrola durante todas as temporadas da série. Ou seja, existe uma história mais aparente, que causa surpresas no final de cada episódio, mas existe uma "história secreta", a qual também vai apresentando suas surpresas, mas que será revelada apenas em sua totalidade no final da última temporada. Bem, essa é, pelo menos, a promessa feita, aquela que se espera ser cumprida, mas que pode ser cortada caso o seriado não tenha uma boa audiência.

Assim é o seriado, assim é o conto, segundo Píglia: "O efeito de surpresa se produz quando o final da história secreta aparece na superfície" (Píglia, 2004, p. 90). A partir dessa ideia pretende-se comparar e entender as duas histórias do conto e do seriado.

\section{As duas histórias e o seriado}

A televisão nasce sob a marca da comunicação de massa. Ou seja, três coisas são indispensáveis para a sua sobrevivência: a produção em massa de programação para satisfazer os seus milhares de receptores, a tecnologia de transmissão, e a audiência. Nesse sentido não se pode enganar, pois um dos grandes poderes na decisão se uma produção deve ser exibida, ou deve continuar a ser exibida, é a estatística, a média de audiência, que deve manter um determinado valor.

O meio frio da TV incentiva a criação de estruturas em profundidade no mundo da arte e do entretenimento criando ao mesmo tempo um profundo envolvimento da audiência. Quase todas as tecnologias e entretenimentos que se seguiram a 
Gutenberg não têm sido meios frios, mas quentes; fragmentários, e não profundos; orientados no sentido do consumo e não da produção (McLuhan 1996, p. 350).

Não é à toa que Paul Lazarsfeld e Robert Merton acrescentaram às funções sociais da comunicação de Harold Lasswell, uma quarta função: o entretenimento. Afinal, através desse formato, é que, muitas vezes as emissoras de TV, conseguem aumentar as suas audiências, valorizando o espaço de mídia vendido para os anunciantes. "Dois sociólogos, Paul F. Lazarsfeld (19011976) e Robert Merton (nascido em 1910), acrescentam a essas três funções (sociais de Harold Lasswell) uma quarta, o entertainment ou diversão (...)" (Mattelart, 1999, p. 42, grifo no original). Sendo assim, a TV reforça a produção industrial de cultura denominada Indústria Cultural (Adorno e Horkheimer, 2000), tão criticada pela Escola de Frankfurt, por Theodor Adorno e Max Horkheimer. Essa produção industrial de cultura é criticada, pois segue o tipo de produção realizada em qualquer indústria: produção em larga escala, padronizada e em série. Ou seja, para otimizar os custos e ampliar os lucros, a indústria pratica uma produção seriada. Deixando a questão crítica para outros debates, essa produção seriada é uma das características mais marcantes, segundo Arlindo Machado, da linguagem desenvolvida pela Televisão.

Há várias explicações sobre as razões que levaram a televisão a adotar a serialização como a principal forma de estruturação de seus produtos audiovisu ais. Para muitos, a televisão, muito mais do que os meios anteriores, funciona segundo um modelo industrial e adota como estratégia produtiva as mesmas prerrogativas da produção em série que já vigoravam em outras esferas industriais, sobretudo na indústria automobilística (Machado, 2000, p. 85-86).

Contudo, antes de continuar esse debate, cabe lembrar que esse formato de produção em série não foi, segundo Arlindo Machado (2000), criado para a TV ou para os meios elétricos em geral, mas que já era utilizado na produção escrita, desde a antiguidade.

Mas é preciso considerar que não foi a televisão que criou a forma seriada de narrativa. Ela já existia antes nas formas epistolares de literatura (cartas, sermões, etc.), nas narrativas míticas intermináveis (As mil e uma noites), depois teve um imenso desenvolvimento com a técnica do folhetim, utilizada na literatura publicada em jornais no século passado, continuou com a tradição do radiodrama ou da radionovela e conheceu a sua primeira versão audiovisual com os seriados do cinema. Na verdade, foi o cinema que forneceu o modelo básico de serialização audiovisual de que se vale hoje a televisão (Machado, 2000, p. 86, grifos no original).

Mesmo num olhar antropológico, pela oralidade, através das histórias épicas contadas nas tribos e perpetuadas de geração em geração desde o período neolítico, já se observa esse tipo de narrativa que se apresenta através de diversas aventuras independentes que vão se ligando a uma história maior, e que caminha para o seu final. Essas aventuras parecem desenvolver as habilidades necessárias para que o protagonista possa cumprir a sua sina.

Essa produção em série é traduzida nos meios de comunicação de massa pela criação de programas que também são emitidos através de uma serialidade. Para Arlindo Machado "Chamamos de serialidade essa apresentação descontínua e fragmentada do sintagma televisual" (Machado, 2000, p. 83, grifos no original). Essa estrutura das séries, comuns aos programas televisivos, é denominado porLev Manovich como estruturas fractais:

Estrutura fractal da nova mídia [...]. Da mesma forma que um fractal apresenta a mesma estrutura em diferentes escalas, o objeto da nova mídia sempre apresenta a mesma estrutura modular. Os elementos da mídia, sejam imagens, sons, formas ou comportamentos, são representados como coleções [...], elementos que são agrupados em objetos em uma escala maior, mas que ainda mantêm suas identidades separadamente. Os objetos em si podem ser combinados, dando origem a objetos ainda maiores; sem nenhum deles perder, sua independência (Manovich, 2005, p. 75-76, tradução nossa)².

As estruturas fractais das séries seguem uma forma comum, onde as histórias são apresentadas em episódios, onde cada episódio pode apresentar uma aventura independente, mas com personagens fixos, ou, o que ocorre mais frequentemente na contemporaneidade, episódios com histórias às vezes independentes, mas ligadas a uma trama maior, que envolve um desenrolar mais lento, por uma temporada, ou por todas. 
Muito frequentemente, esses blocos incluem, no início uma pequena contextualização do que estava acontecendo antes [...] e, no final um gancho, que visa manter o interesse do espectador até o retorno da série depois do break ou no dia seguinte (Machado, 2000, p. 83, grifos no original).

Apesar da crítica da Escola de Frankfurt, que vê na reprodução industrial de expressões culturais, segundo Walter Benjamin (2000), a perda da "Aura", da originalidade, Arlindo Machado, rejeita essa visão de mera reprodução, e afirma que a TV e sua serialidade acabam por criar uma "estética da repetição" (Machado, 2000, p. 90).

Omar Calabrese, por sua vez, rejeitando o senso comum que considerava o repetitivo e o serial como o contrário do original e do artístico, vem a afirmar que a produção seriada da televisão nos permite pensar numa coisa nova, uma espécie de "estética da repetição", baseada na dinâmica que brota da relação entre os elementos invariantes e os variantes (Machado, 2000, p. 90).

Finalmente, o seriado, com a sua história secreta, apresenta a possibilidade de participação do espectador, pois deixa espaços na trama entre um episódio e outro. Espaços na história a serem preenchidos por quem assiste. A participação, segundo McLuhan, é uma característica da TV.

A imagem da TV exige que, a cada instante, "fechemos" os espaços da trama por meio de uma partici- pação convulsiva e sensorial que é profundamente cinética e tátil, porque a tatilidade é a inter-relação dos sentidos, mais do que o contato isolado da pele e do objeto (McLuhan, 1996, p. 352).

Essa participação no imaginário das tramas que a TV, através dos seriados possibilita, mostra-se também muito interessante para os novos meios digitais, a lnternet e as redes sociais, pois a fragmentação, a mobilidade e a interação são características básicas desses novos canais, e qualidades esperadas pelo grande público. Todo meio de comunicação atual, que espera alcançar uma audiência de expressão, precisa possibilitar cada vez mais a participação dos espectadores.

Por essas questões que a estrutura do seriado se encaixa tão bem com a dinâmica da programação televisiva, ambos funcionam bem em um sistema de produção industrial: seriado, flexível (apresenta a possibilidade de ser adequado conforme o público e as taxas de audiência) e passível de ser feito em larga escala. O seriado, também, promove a participação do espectador no preenchimento de espaços em sua trama, característica valorizada e esperada em meios de comunicação como a TV e, mais contemporaneamente, pelos meios digitais e a Internet, com suas redes sociais. Além disso, os debates que essas redes sociais e os meios digitais possibilitam entre os fãs de seriados, criam interações constantes que interferem no interesse do público por determinada série contribuindo com o aumento e diminuição da audiência o que pode definir a sua continuidade ou o seu encerramento. Essa é a dinâmica dos meios de comunicação atuais, e o todos esperam um espaço para interagir com a programação.
A elipse, o labirinto e a comparação do conto e do seriado

Talvez um dos mais conhecidos contos de Jorge Luis Borges, O Jardim de Veredas que se Bifurcam, publicado no livro Ficções (1999), pode-se considerar um modelo exemplar da estrutura narrativa de um conto, principalmente dos contos de Borges. Nele, como é comum nos textos de Borges, a narrativa começa em uma história, baseada em algum documento incompleto, secreto ou recém descoberto, que levanta dúvidas sobre algumas questões, e se desdobra em outras histórias, antes de retornar à inicial. Esses desdobramentos para dentro das diversas histórias constitui-se em um efeito que cria uma estrutura enigmática. A história dentro de outra história, dentro de outra história: essa é uma estratégia do escritor, que vai construindo sua narrativa de forma labiríntica. Propondo diversas histórias em que o leitor vai caindo no abismo de cascatas, que são as tramas intrincadas propostas pelo autor, de forma que vai se perdendo e, ao mesmo tempo, buscando o fio de Ariadne na narrativa, para que possa sair do vertiginoso conto labiríntico.

Em particular, no conto O Jardim de Veredas que se Bifurcam, Borges inicia a trama na "página 242 da História da Guerra Européia, de Liddel Hart" (Borges, 1999, p. 88) e descreve acontecimentos da II Guerra Mundial. Esses acontecimentos nos levam a Ts'ui Pen, através de um bisneto dele envolvido na trama atual da guerra. Ts'ui Pen, segundo a narrativa, teria se retirado em determinado momento para escrever um livro e construir um labirinto. O livro já havia sido localizado, mas o labirinto não, o que aumentava o mistério em torno de Ts'ui Pen. Mistério esse solucionado, quando se desco- 
bre que, na verdade, livro e labirinto se constitui como sendo o mesmo objeto.

Ts'ui Pen teria dito uma vez: 'Retiro-me para escrever um livro'. E outra: 'Retiro-me para construir um labirinto'. Todos imaginaram duas obras; ninguém pensou que livro e labirinto eram um único objeto (Borges, 1999, p. 95).

Acabou a trama? Não. Borges (1999) nesse momento nos transporta novamente para a trama inicial e nos surpreende com a saída do labirinto que alinhava todas as histórias, quando um espião alemão apenas queria transmitir a informação de qual cidade deveria ser bombardeada. Segundo Píglia "Um relato visível esconde um relato secreto, narrado de um modo elíptico e fragmentário" (Píglia, 2004, p. 90), enfim, labiríntico.

Essa estrutura labiríntica e elíptica parece agradar o sujeito da contemporaneidade, denominado, por Stuart Hall (2004): sujeito pós-moderno. O sujeito pós -moderno está acostumado a constituir suas representações estéticas à partir da intertextualidade, que seria segundo Roland Barthes (2004), o cruzamento de culturas e das mais diferentes referências. Leda Tenório da Motta diz que "[...] a teoria da intertextualidade supõe uma apropriação mútua dos autores e dos textos [...]" (Motta, 2011, p. 241), concordando dessa maneira com Barthes que afirma:

[...] um texto é feito de múltiplas escrituras, elaboradas a partir de diversas culturas e ingressante em uma relação mútua de diálogo, paródia, contestação; mas há um lugar em que esta multipli- cidade é percebida, e este lugar [...] é o leitor: o leitor é o espaço em que se inscrevem, sem que nenhuma se perca, todas as citações que constituem a escritura: a unidade do texto não reside em sua origem, mas em seu destino, e este destino não pode ser pessoal: o leitor é alguém sem história, sem biografia, sem psicologia; ele é, simplesmente, um qualquer que articula, em um único campo, todos os traços a partir dos quais se constitui a escritura (Barthes, 2004, p. 64).

Mas, além do sujeito pós-moderno, o período Barroco também apresenta esse gosto pela intertextualidade e, assim como no momento contemporâneo, ambos apresentam características similares na produção estética e no pensamento: uso de paródias e citações/intertextualidade, jogos poéticos, estruturas labirínticas, excessos decorativos, identidade inconstante e adaptação constante de suas metanarrativas, entendendo metanarrativas como os discursos internos e fundadores que compõem o pensamento de uma cultura (Strinati, 1999). Esses discursos se apresentam nas narrativas familiares, na mídia, na religião, no ambiente familiar e acabam por influenciar a formação dialética da cultura mediando as relações entre cultura, humano e sociedade.

Severo Sarduy (1987) reconhece essa proximidade entre esses períodos, a saber o Barroco (por volta dos séculos XVII, XVIII), e da Pós-modernidade (por volta dos séculos $X X$ e $X X I$ ), e prefere denominar o momento contemporâneo como Neobarroco. Dessa forma, a narrativa contemporânea, inserida na Pós-modernidade, não poderia deixar de apresentar essas características elípticas, e como se tem observado nesse artigo, que, tanto atinge a estrutura narrativa do conto, como a estrutura narrativa do seriado de TV.

Uma emissão diária de um determinado programa é normalmente constituída por um conjunto de blocos, mas ela própria também é um segmento de uma totalidade maior - o programa como um todo - que se espalha ao longo de meses, anos, em alguns casos até décadas, sob a forma de edições diárias, semanais ou mensais (Machado, 2000, p. 83, grifos no original).

Assim como o conto de Borges, os seriados de TV parecem desenvolver essas estruturas elípticas e labirínticas, percebido nesse desdobramento interno das histórias, como Machado:

No primeiro caso, temos uma única narrativa (ou várias narrativas entrelaçadas e paralelas) que se sucede $(m)$ mais ou menos linearmente ao longo de todos os capítulos. [...] Esse tipo de construção se diz teleológico, pois ele se resume fundamentalmente num (ou mais) conflito(s) básico(s), que estabelece logo de início um desequilíbrio estrutural, e toda evolução posterior dos acontecimentos consiste num empenho em restabelecer o equilíbrio perdido, objetivo que, em geral, só se atinge nos capítulos finais (Machado, 2000, p. 84, grifos no original).

Once Upon a Time (2011), Grimm (2011), Supernatural (2005), The Ranch (2016), 3\% (2016), A Lenda de Sleepy Hollow (2013), How to get Away with Murder (2014), 
O Hipnotizador (2015), são alguns exemplos de seriados que se organizam nessa estrutura em abismo/Mise en Abyme: elíptica e labiríntica. Ou seja, cada capítulo parece buscar uma independência, ao mesmo tempo que faz parte de uma história maior que se desenrola entremeada às tramas dos capítulos. Onde inicia e termina essa relação, qual o limite para cada uma das tramas está sempre envolta de névoas, obscura, misteriosa e indefinida, pelo menos até os episódios finais.

The Blacklist (2013) é um dos modelos exemplares de seriado, tramas individuais que vão se solucionando, a maioria das vezes, no próprio episódio, e a história secreta, a grande trama que amarra todas as temporadas da série, aquela que cria constantemente os espaços para serem preenchidos pela imaginação dos espectadores, e que mantém a proliferação de debates sobre a série nas redes sociais, possibilitando, assim, a ampliação do interesse do público e o consequente aumento da audiência.

A lista negra que é sugerida pelo título da série, se trata de uma lista de criminosos que Raymond Reddington passa a entregar às autoridades americanas. Um por vez, um por episódio. Cada um dos episódios, a princípio, é organizado para revelar um criminoso, seus hábitos, características e habilidades, além de mostrar como ele seria preso através do protagonismo, tanto da agente Keen, como por Reddington. Contudo, a história não acaba nesse episódio. Existe uma trama maior, mais intrincada, que a cada momento parece querer se resolver, mas que acaba por criar outras novas interpretações, outras tramas a serem resolvidas. Nessa segunda trama, a história secreta, que se desenrola por todas as temporadas, um dos maiores mistérios envolve a paternidade e a infância misteriosa da agente Keen, onde, por vezes, parece ser filha de Reddington. Essa estrutura de texto lembra muito as peripécias e os reconhecimentos utilizados nas tragédias gregas e descritas por Aristóteles em seu livro Arte Poética (2004).

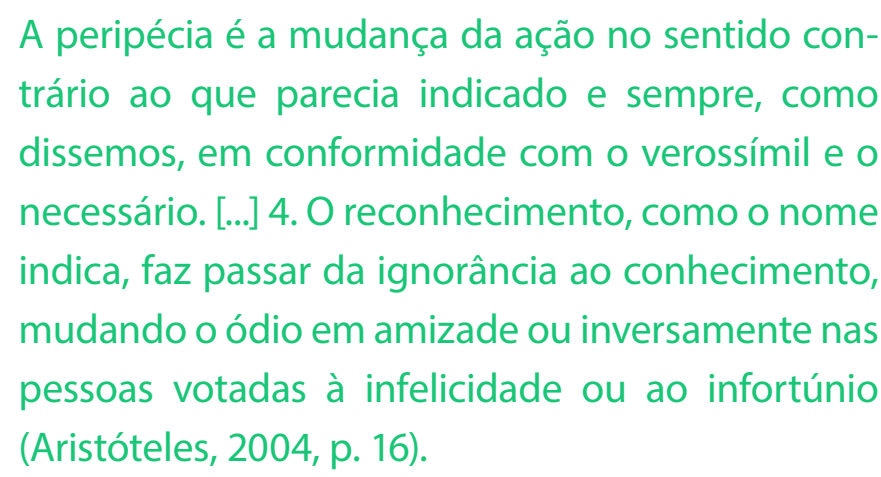
trário ao que parecia indicado e sempre, como dissemos, em conformidade com o verossímil e o necessário. [...] 4. O reconhecimento, como o nome indica, faz passar da ignorância ao conhecimento, mudando o ódio em amizade ou inversamente nas pessoas votadas à infelicidade ou ao infortúnio (Aristóteles, 2004, p. 16).

Assim como em uma tragédia grega, The Blacklist e outros seriados apresentam em sua história secreta momentos em que você reconhece na trama algumas informações que possibilitariam você, espectador, a resolver o mistério. No entanto, isso não é tão fácil, pois existem muitas temporadas ainda a serem transmitidas, pois a cada reconhecimento, quando parece que tudo será resolvido, aparece uma peripécia, ou seja, uma inversão na trama. Na peripécia, o que parecia se resolver, acaba tornando mais obscura a solução da trama.

Enfim, de peripécias e reconhecimentos é que um seriado consegue envolver seu espectador, consegue manter o interesse elevaro público à participação. Dessa forma, assim como o conto literário, os seriados utilizam a história secreta na sua estrutura narrativa, e essa estratégia parece alimentar e cativar o interesse, tanto do leitor, quanto do espectador, transformando-se assim, uma técnica que deve ser observada e compreendida por quem quer estudar ou produzir qualquer um desses suportes de comunicação: seja o conto, seja a série.

\section{Considerações Finais}

Após a observação e análise das semelhanças entre a estrutura dos contos e a dos seriados televisivos, pode-se destacar, principalmente, o uso da segunda trama, a qual somente é revelada após um contato maior com as histórias que permeiam essas duas formas de linguagem: a escrita e a visual. Percebe-se também que o formato seriado se encaixa bem, tanto às formas de produção contemporâneo dos meios de comunicação de massa, meios digitais (redes sociais, internet), como também ao gosto do público, que se envolve com as séries e desenvolve uma busca. Esse público busca não apenas pela solução do mistério do episódio, mas como nas tragédias gregas, o espectador se interessa pelas peripécias e reconhecimentos que os seriados vão criando. Dessa maneira, esse espectador busca participar do esclarecimento de toda a intrincada trama, que, na maioria das vezes, somente se resolve no final da série.

Um fator que também impulsiona a audiência das séries televisivas é a possibilidade de acompanha-las em qualquer hora, em qualquer lugar. Outrora, aquele que acompanhava as séries pela televisão, ficava à mercê dos horários das emissoras, e tinha que compatibilizar suas disponibilidades com esses horários. Agora, com os meios de comunicação digital, a internet, e as plataformas on demand, como o Netflix, ou a Amazon, o espectador pode acompanhar suas séries favoritas na hora que ele desejar ou puder.

"Nós descobrimos que a forma como as pessoas assistem às séries mudou. Não é mais apenas pela manhã ou à noite, mas em dispositivos móveis a caminho do trabalho e ao longo do dia", diz André 
Gualda, analista do consumer Lab da Ericsson (Lima, 2014, grifos no original).

Participação, interação, mobilidade: esses ingredientes dos meios de comunicação digital acabaram por fazer proliferar a produção e transmissão das séries, assim como a multiplicação da sua audiência. Com isso, para dar conta dessa nova relação entre o público e as séries, os produtores tiveram que utilizar de estratégias que aumentassem o envolvimento do espectador, fazendo com que ele participasse mais ativamente das tramas, e que se torna-se um verdadeiro coadjuvante da disseminação e do sucesso dessas criações televisivas.

Observando a proliferação das séries e o aumento da audiência, acredita-se, nessa pesquisa, que o estudo da estrutura dos contos, com suas complexidades, e com as suas histórias múltiplas, pode servir como uma fonte de inspiração para novos produtos televisivos, além de possibilitar as reflexões para o desenvolvimento das tramas dos seriados.

\section{Referências Bibliográficas}

ADORNO, T. e HORKHEIMER, M. Indústria Cultural: O lluminismo como Mistificação das Massas. In: LIMA, L. C. (org.). Teoria da Cultura de Massa. São Paulo: Paz \& Terra, 2000. p. 169-214.

ARISTÓTELES. Arte Poética. 2001. Disponível em: < http://www.dominiopublico.gov.br/pesquisa/DetaIheObraForm.do?select_action $=\&$ co_obra $=2235>$. Acesso em: 16 jun. 2017.

BARTHES, R. O Rumor da Língua. São Paulo: Martins Fontes, 2004.
BENJAMIN, W. A Obra de Arte na Época de sua Reprodutibilidade Técnica. In: LIMA, L. C. (org.). Teoria da Cultura de Massa. São Paulo: Paz \& Terra, 2000. p. 221-254.

BORGES, J. L. Ficções. São Paulo: Globo, 1999.

GOTLIB, N. B. Teoria do Conto. São Paulo: Brasiliense, 2006.

HALL, S. A Identidade Cultural na Pós-modernidade. Rio de Janeiro: DP\&A, 2004.

LIMA, L. C. (org.). Teoria da Cultura de Massa. São Paulo: Paz \& Terra, 2000.

LIMA, I. M. Pesquisa revela que jovens solteiras são as maiores viciadas em séries. Folha de São Paulo. São Paulo, 6 abr. 2014. Disponível em: <http://f5.folha.uol. com.br/televisao/2014/04/1436727-pesquisa-revelaque-jovens-solteiras-sao-as-maiores-viciadas-emseries.shtml>. Acesso em: 02 dez. 2015.

\section{MANOVICH, L. El Lenguaje de los Nuevos Medios de} Comunicación. Barcelona: Paidós, 2005.

MACHADO, A. A Televisão Levada à Sério. São Paulo: Senac, 2000.

MCLUHAN, M. Os Meios de Comunicação como Extensões do Homem. São Paulo: Cultrix, 1996.

MATTELART, A.; MATTELART, M. História das Teorias da Comunicação. São Paulo: Loyola, 1999.

MOTTA, L. T. Roland Barthes: Uma Biografia Intelectual. São Paulo: Iluminuras/ Fapesp, 2011.

PÍGLIA, R. Formas Breves. São Paulo: Companhia da Letras, 2004.

SARDUY, S. Ensayos Generales Sobre el Barroco. Buenos Aires: FCE, 1987.

STRINATI, D. Cultura Popular. São Paulo: Hedra, 1999.

\section{Referências Audiovisuais}

AGUILERA, Pedro. 3\%. [Tv-series]. Produção de Boutique Filmes. Brasil, 2016, 49 min. Cor. Som.

BOKENKAMP, J. The Blacklist. [Tv-séries]. Produção de Davis Entertainment, Universal Television e Sony Pictures Television. Estados Unidos, 2013, 43 min. Cor. Som.

CARPENTER, Stephen. GREENWALT, David. KOUF, Jim. Grimm. [Tv-series]. Produção de GK Productions, Hazy Mills Productions, Universal Television. Estados Unidos, 2011, 45 min. Cor. Som.

DE JESUS, Maria Angela. RIOS, Roberto. TEIXEIRA, Rodrigo. PERAZA, Luis. El Hipnotizador. [Tv-series]. Produção de HBO Latin America, RT Features. 2015, Argentina/Brasil/Uruguay, $60 \mathrm{~min}$. Cor. Som.

HOROWITZ, Adam. KITSIS, Edward. Once upon a time. [Tv-series]. Produção de Kitsis/Horowitz, ABC Studios. Estados Unidos, 2011, 44 min. Cor. Som. 
ISCOVE, Phillip. KURTZMAN, Alex. ORCI, Roberto. Sleepy Hollow. [Tv-series]. Produção de Sketch Films, K/O Paper Products, $20^{\text {th }}$ Century Fox Television. Estados Unidos, 2013, $45 \mathrm{~min}$. Cor. Som.

KRIPKE, Eric. Supernatural. [TV-series]. Produção de Kripke Enterprises, Warner Bros. Television, Wonderland Sound and Vision. Estados Unidos, 2005, 45 min. Cor. Som.

NOWALK, Peter. How to get away with murder. [TV-series]. Produção de Shondaland, Nowalk Entertainment, ABC Studios. Estados Unidos, 2014, 43 min. Cor. Som.

PATTERSON, Jim. REO, Dom. The Ranch. [Tv-series]. Produção de Ranch Hand Productions. Estados Unidos, 2016, 30 min. Cor. Som.

\section{Notas}

1 Doutor em Comunicação e Semiótica pela Pontifícia Universidade Católica de São Paulo (2013). Mestre em Comunicação e Semiótica pela Pontifícia Universidade Católica de São Paulo (2001). Professor das áreas de Comunicação e Artes da Universidade Presbiteriana Mackenzie (Universidade Presbiteriana Mackenzie. Rua da Consolação, 930. Consolação. Cep: 01302907 São Paulo, SP - Brasil). E-mail: patricio@mackenzie.br.

2 No original: "Estructura fractal de los nuevos medios [...]. De la misma manera que un fractal pose ela misma estructura a diferentes escalas, el objeto de los nuevos medios presenta siempre la misma estructura modular. Los elementos mediáticos, ya sean imágenes, sonidos, formas o comportamientos, son representados como colecciones de musestras discretas [...], unos elementos que se agrupan en objetos a mayor escala, pero que siguen manteniendo sus identidades por separado. Los propios objetos pueden combinarse a su vez dando lugar a objetos aún más grandes; sin perder, ellos tampoco, su independencia" (Manovitch, 2005, P. 75 e 76). 